\title{
A teoria polifônica de Ducrot e a análise do discurso
}

\author{
Sílvia Helena Barbi \\ Universidade Federal de Minas Gerais
}

\section{Abstract}

This article compares the most significant advances made by French Discourse Analysis (DA), developed by a team of researchers under the pioneering leadership of Michel Pêcheux, with the "polyphonic theory' developed by Oswald Ducrot. While DA develops an important framework for discourse analysis which firmly situates discourse in a broader context of social relations, Ducrot's approach is not interested in the concepts of 'ideology' and 'power'. If this crucial difference is taken into consideration, Oswald Ducrot's polyphonic theory may be used by discourse analysts as one approach among others for investigating the interplay between the 'voices' of discourse. 


\section{INTRODUÇÃO}

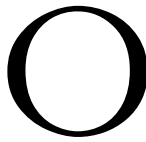

fato de se encontrarem elementos das teorias de Oswald Ducrot em alguns conceituados manuais de Análise do Discurso de linha francesa (AD) não deixa de ser uma questão instigante. Ducrot enuncia do interior da "Pragmática Semântica" ou da "Pragmática Lingüística", lugar em que ele próprio reconhece situarem-se suas pesquisas (Ducrot, 1984:163), lugar, digase de passagem, não muito comprometido com a questão central da $\mathrm{AD}$, que é a existência de um além interdiscursivo como elemento constitutivo de todo discurso, que se impõe aquém do autocontrole do sujeito enunciador.

Usando as palavras da própria $\mathrm{AD}$, que em seu momento atual tem priorizado a questão da heterogeneidade discursiva, é possível dizer que o trabalho de Oswald Ducrot se relaciona com a AD como "o discurso de um outro", colocado em cena pelo sujeito AD.

No desenvolvimento atual de numerosas pesquisas sobre os encadeamentos "intradiscursivos - interfrásticos", que permite, no dizer de Pêcheux, "abordar o estudo da construção dos objetos discursivos e dos acontecimentos, e também dos "pontos de vista" e lugares enunciativos no fio intradiscursivo" (Pêcheux, 1983:316), os trabalhos de Ducrot, em especial os relativos à questão da polifonia, têm sido citados com muita freqüência pelos analistas do discurso. Ao mesmo tempo, o autor de Esboço de uma teoria polifônica da enunciação faz referências a importantes trabalhos da $\mathrm{AD}$, sobretudo aos de Pêcheux e Authier-Revuz, para não citarmos outros.

Dominique Maingeneau, em seu trabalho Novas tendências em análise do discurso, utiliza conceitos de Ducrot, no que diz respeito à heterogeneidade enunciativa, um dos temas magnos da atual AD, 
sem contudo deixar de alertar que essa não é a única abordagem lingüística que considera os fatos de polifonia. À abordagem de Ducrot seguem-se, nessa obra, elementos da abordagem de AuthierRevuz assim como elementos da própria abordagem de Maingeneau. Elementos da teoria polifônica de Ducrot de 1984, e de outros trabalhos anteriores do autor, ocupam lugares de destaque nas publicações mais recentes de Maingeneau, sobretudo Elementos de lingüística para o texto literário, de 1986, e Pragmática para o discurso literário, de 1990.

Entre nós, sem qualquer embaraço, alguns estudiosos da AD valem-se constantemente dos trabalhos de Ducrot para abordar as questões relativas às formas lingüístico-discursivas do discurso-outro, muito embora as questões colocadas por Ducrot não estejam comprometidas com a determinação histórica dos sujeitos e dos sentidos.

Como se sabe, a Análise do Discurso Francesa, sob a liderança de Michel Pêcheux, se constituiu pela necessidade de uma teoria materialista do discurso, que desmascarasse a "evidência" da existência espontânea do sujeito (como origem e causa de si mesmo), assim como a "evidência" do sentido. Afirmando que ambas as evidências sustentam a filosofia idealista da linguagem, e colocando-se contra esse idealismo, Pêcheux propôs, então, uma teoria materialista dos processos discursivos, articulada com a problemática das condições ideológicas de reprodução/transformação das relações de produção.

O momento atual, em que se busca entender o discurso não só como repetição de já-ditos, mas como acontecimento discursivo, não abriu mão contudo da recusa de "qualquer metalíngua universal inscrita no inatismo do espírito humano, e de toda suposição de um sujeito intencional como origem enunciadora de seu discurso" (Pêcheux, 1983a:311).

Tendo em vista essas considerações, achamos pertinente fazer uma reflexão sobre a relação da AD com esse seu "outro", que constitui a teoria polifônica de Ducrot, enfocando as possíveis 
contribuições para com a $\mathrm{AD}$, apesar das diferenças teóricas. Privilegiamos nesta análise o trabalho de Ducrot (1984), Esboço de uma teoria polifônica da enunciação.

\section{MARCANDO DIFERENÇAS}

\subsection{O conceito de enunciado}

Para Ducrot, o enunciado é uma entidade observável, uma ocorrência bic e nunc de uma frase, sendo essa uma entidade lingüística, um objeto teórico de domínio da gramática. É tanto possível afirmar que o enunciado é um fragmento do discurso, como afirmar que o discurso se constitui de um só enunciado. Nos dois casos, deve-se considerar o discurso como um fenômeno observável. No primeiro caso, o discurso é considerado como sendo constituído de uma seqüência linear de enunciados e cada enunciado correspondendo a uma escolha pelo sujeito falante, escolha relativamente autônoma de um enunciado em relação à escolha dos outros. No segundo caso, em que se considera um discurso formado de um só enunciado, supõe-se que o falante o apresentou como objeto de uma única escolha.

O conceito de autonomia relativa, no primeiro caso, deve satisfazer às condições de coesão e independência. Há coesão quando a escolha de cada constituinte é determinada pela escolha do conjunto. Uma seqüência é independente quando sua escolha não é imposta pela escolha de um conjunto mais amplo de que faz parte. ${ }^{1}$

Definidos como fragmentos do discurso, os enunciados se opõem às frases de uma língua, entidades teóricas, subjacentes aos enunciados que se realizam através dessa língua.

A separação entre essas duas entidades diz respeito a uma diferença de estatuto metodológico, relativo, pois, ao ponto de vista escolhido pela pesquisa, e não a uma diferença empírica entre elas, em que uma seria de ordem perceptiva e outra de ordem intelectual. 
Muito diferente é a concepção de enunciado que se tem na AD. Para compreendermos essa concepção, necessário se faz que consideremos os diferentes momentos ou gerações da $\mathrm{AD}$ (Pêcheux, 1983a).

Para a segunda geração da análise do discurso, que tomou os conceitos de enunciado e de discurso de Foucault (1969), o enunciado extrapola o domínio do discurso enquanto acontecimento, enquanto escolha de um falante. O enunciado é, sim, uma unidade de discurso, mas o discurso, considerado enquanto um conjunto de enunciados que pertencem à mesma formação discursiva, não se limita ao acontecimento. O enunciado acaba por constituir a materialidade repetível de uma determinada formação discursiva. Trata-se de uma formação discursiva (Foucault, 1969:43) quando se pode descrever, entre um certo número de enunciados, um sistema de dispersão, no qual entre os objetos, os tipos de enunciação, os conceitos, as escolhas temáticas, pode-se definir uma regularidade (uma ordem, correlações, posições e funcionamentos, transformações).

Partindo desse conceito de Foucault e comprometido com o materialismo histórico, Pêcheux (1975:160) afirma que uma formação discursiva é "aquilo que, numa formação ideológica dada, isto é, a partir de uma posição dada numa conjuntura dada, determinada pelo estado da luta de classes, determina o que pode e deve ser dito (articulado sob a forma de uma arenga, de um sermão, de um panfleto, de uma exposição, de um programa, etc.)".

Nas palavras de Foucault, um enunciado é sempre um acontecimento, o qual, nem a língua nem o sentido podem esgotar inteiramente. É único, mas está aberto à repetição, à transformação, à reativação. Ligado a situações que o provocam, e a consequências por ele ocasionadas, mas, ao mesmo tempo, e segundo uma modalidade inteiramente diferente, a enunciados que o precedem e o seguem, constitui "o nó em uma rede" (Foucault, 1969:32).

O discurso é, pois, acontecimento e uma prática regulamentada, que conta de um certo número de enunciados. Não se 
confundindo com o texto, que constitui a manifestação verbal do discurso, o discurso é lido e ouvido sob a forma de texto.

Por "prática" não se entende só a atividade de um sujeito, mas a existência objetiva e material de certas regras às quais o sujeito tem de obedecer quando participa do discurso. As relações discursivas não se reduzem, portanto, a relações internas ao discurso, nexos que existem entre conceitos ou palavras, frases ou proposições, o que equivale a dizer, nos termos de Pêcheux (1975), que as relações discursivas não se reduzem ao intradiscurso, ou ao "fio do discurso" de um sujeito. As relações discursivas determinam o feixe das relações que o discurso deve manter para ter condições de tratar de determinados objetos, e processá-los, nomeá-los, analisá-los, classificá-los, explicá-los, etc.

Unidade elementar do discurso, uma função que cruza um domínio de estruturas e de unidades possíveis, o enunciado não poder ser considerado independentemente das formações discursivas, que constituem unidades formadas a partir das relações que podem ser legitimamente descritas entre os enunciados, deixados em seu grupamento provisório e visível. Tratando-se de um princípio de dispersão e de repartição de enunciados (não de frases, de proposições ou atos de fala), cada formação discursiva é concebida como um sistema enunciativo geral ao qual obedece um grupo de performances verbais.

Sendo dispersões, lacunas, falhas, desordens, superposições, incompatibilidades, trocas e substituições, as formações discursivas podem, no entanto, ser descritas em sua singularidade se formos capazes de determinar as regras específicas segundo as quais foram formados objetos, enunciações, conceitos e opções teóricas e definir em sua unidade singular um sistema de formação e, assim, caracterizar um discurso ou um grupo de enunciados pela regularidade de uma prática.

A formação discursiva foi todavia muitas vezes entendida, no interior da AD, como um bloco estrutural, homogêneo, o que fez com que não se desse conta do discurso enquanto acontecimento, 
enquanto discurso de um sujeito. A existência desse espaço social e de memória histórica em que se situam os enunciados acabou por absorver o acontecimento desse discurso na estrutura da série na medida em que esta tendia a funcionar como "transcendental histórico", "grade de leitura" ou de "memória antecipadora do discurso em questão”, como reconhece o próprio Pêcheux:

“(...) o gesto que consiste em inscrever o discurso em tal ou tal série,
a incorporá-lo a um 'corpus', corre o risco de absorver o
acontecimento. A noção de 'formação discursiva' emprestada a
Foucault pela análise do discurso derivou muitas vezes para a idéia
de uma maquinaria discursiva de assujeitamento dotada de uma
estrutura semiótica e por isso mesmo voltada à repetição: no limite,
esta concepção estrutural da discursividade desembocaria em um
apagamento do acontecimento, através da absorção em uma sobre-
interpretação antecipadora” (Pêcheux, 1983b:56).

É por essa razão que na perspectiva atual da $\mathrm{AD}$, define-se uma formação discursiva a partir de seu interdiscurso, o que equivale a afirmar que uma formação discursiva não deve ser concebida como um bloco compacto, homogêneo, que se opõe a outros, mas como uma realidade heterogênea por si mesma. O interdiscurso é concebido como um processo de reconfiguração incessante no qual uma formação discursiva, um domínio aberto e inconsistente (e não a expressão estabilizada da "visão de mundo" de um grupo social), é levada a incorporar elementos pré-construídos, produzidos fora dela. Com esses elementos, ela se redefine e se redireciona, ao mesmo tempo que chama seus próprios elementos para organizar sua repetição, o que provoca, eventualmente, o apagamento, o esquecimento ou mesmo a denegação de determinados elementos. A formação discursiva aparece, assim, como lugar de um trabalho no interdiscurso.

Uma maneira de compreender esse "nó" de que se constitui o enunciado nos é dada por Courtine (1981). O enunciado é colocado na intersecção de dois eixos: um "vertical", ou do pré-construído que o interdiscurso impõe; e um eixo "horizontal", linear, da seqüência 
discursiva no interior do intradiscurso. Deve-se entender intradiscurso no sentido que lhe deu Pêcheux (1975:166): o eixo linear do funcionamento do discurso com relação a si mesmo, abrangendo os fenômenos de co-referência, que garantem o "fio do discurso" enquanto discurso de um sujeito. Por interdiscurso deve-se entender uma articulação contraditória de formações discursivas que se referem a formações ideológicas antagônicas, um "além” que, aquém de todo autocontrole do sujeito enunciador, se impõe estruturando a cena enunciativa do sujeito enunciador ao mesmo tempo que a desestabiliza.

Procuraremos a seguir mostrar, de maneira esquemática, algumas diferenças entre os conceitos de enunciado de Ducrot e o da A.D.

1. Para Ducrot, o enunciado é um acontecimento, é o singular, produzido em um tempo e um lugar determinado. Para a AD, o enunciado não é apenas acontecimento. Ele se insere num ponto de articulação entre um pré-construído, do domínio da memória (memória presumida pelo enunciado enquanto inscrito na história), e o "horizontal", da linearidade do discurso, que oculta o primeiro eixo, já que o sujeito enunciador é produzido como se interiorizasse de forma ilusória o pré-construído que sua formação discursiva impõe.

2. Para Ducrot, o enunciado, enquanto fragmento do discurso, faz parte de um conjunto de enunciados pertencentes à linearidade do discurso. Para a AD, as relações do enunciado não se reduzem à linearidade do discurso. Ele também faz parte de uma série ou de um conjunto, desempenhando um papel no meio dos outros e pressupondo os outros. Essa série ou conjunto, que não se confunde com o intradiscurso ou o fio do discurso de um sujeito, pertence ao interdiscurso, ou o "todo complexo com dominante das formações discursivas", que fornece a "matéria prima" ao discurso do sujeito. Ao domínio da memória desse interdiscurso se associa o domínio da atualidade (Courtine, 
1981), aquele das seqüências que, em torno de um acontecimento, se refutam, se apóiam, etc., em uma conjuntura definida.

3. Para Ducrot, o enunciado não se repete. Cada enunciado suporta apenas uma enunciação: se duas pessoas diferentes dizem uma frase, ou uma mesma pessoa diz em dois momentos diferentes, temos dois enunciados diferentes. Para a AD, o enunciado suporta enunciações distintas, realizadas por uma mesma pessoa ou por pessoas diferentes. Uma mesma frase pronunciada por duas pessoas diferentes pode constituir um mesmo enunciado. Uma informação dada pode ser transmitida com outras palavras, com uma sintaxe simplificada, ou em um código convencionado. Se o conteúdo informativo e as possibilidades de utilização são as mesmas, poderemos dizer que ambos os casos constituem o mesmo enunciado. O enunciado tem existência material e pode ser repetido apesar de sua materialidade, sendo, pois, caracterizado por uma materialidade repetível. O enunciado, ao mesmo tempo que surge em sua materialidade, entra em redes, se coloca em campos de atualização, se oferece a transferências e a modificações possíveis, se integra em operações e em estratégias onde sua identidade se mantém ou se apaga.

\subsection{A questão do sentido}

Opondo "sentido", caracterização semântica do enunciado a "significação", caracterização semântica da frase, Ducrot se opõe a uma concepção habitual que toma o sentido do enunciado como a significação da frase acrescida de alguns ingredientes tomados da situação do discurso. Para o autor, a significação, que não faz parte do sentido, constitui "um conjunto de instruções dadas às pessoas que têm que interpretar os enunciados da frase" (Ducrot, 1984: 170). O sentido do enunciado consiste, por sua vez, na descrição da enunciação, ou ainda, na representação que o enunciado faz de sua enunciação. O sentido é "uma qualificação da enunciação", 
consistindo em atribuir à enunciação não somente certos poderes como também certas conseqüências.

Fazem parte dessa descrição as indicações argumentativas, ilocutórias, expressivas, assim como indicações sobre os autores da enunciação. Em outras palavras: a frase dá, em virtude de sua significação, instruções aos ouvintes que devem construir o sentido do enunciado. A partir do valor da frase, podem-se prever as possibilidades no que concerne aos atos ilocutórios ligados à enunciação, assim como as possibilidades relativas à argumentação. Devem-se considerar ainda, entre suas instruções diretivas, aquelas que distinguem locutores e enunciadores, distinção de que trataremos abaixo. Essas diretivas determinam, no momento em que se interpreta o enunciado, a quem se deve atribuir esses papéis.

O sentido do enunciado, considerado como uma descrição da enunciação, se situa fora de uma dimensão social mais ampla. Ducrot não tem a intenção de construir um conceito bistórico de enunciação. ${ }^{2}$ Quando diz que a enunciação é um "acontecimento histórico", refere-se ao fato de a frase ter sido objeto de um enunciado, ou seja, refere-se a seu caráter temporal, e não às determinações sociais a que pode estar sujeita.

A análise do discurso, por sua vez, defende que o sentido de um enunciado, assim como o de uma palavra ou expressão, é dado no interior da formação discursiva à qual o enunciado pertence, enquanto elemento de ordem institucional, ou elemento de uma prática social (Pêcheux, 1975). O caráter material do sentido consiste na sua dependência constitutiva com "o todo complexo das formações ideológicas". "Não importa quem fala, mas o que ele diz não é dito de qualquer lugar." (Foucault, 1969:142). O discurso não tem apenas um sentido e uma verdade, mas uma história.

Essa dependência histórico-social do sentido é explicitada por Pêcheux por meio de duas teses:

"1) (...) o sentido de uma palavra, de uma expressão, de uma proposição. etc., não existe 'em si mesmo' (isto é, em sua relação transparente com a literalidade do significante), mas, ao contrário, 
é determinado pelas posições ideológicas que estão em jogo no processo sócio-histórico no qual as palavras, expressões e proposições são produzidas (isto é, reproduzidas). Poderíamos resumir essa tese dizendo: as palavras, expressões, proposições, etc., mudam de sentido segundo as posiçôes sustentadas por aqueles que as empregam, o que quer dizer que elas adquirem seu sentido em referência a essas posições, isto é, em referência às formações ideológicas nas quais essas posições se inscrevem." (Pêcheux, 1975:160)

"2) Toda formação discursiva dissimula, pela transparência do sentido que nela se constitui, sua dependência com respeito ao 'todo complexo com dominante' das formações discursivas, intrincado no complexo das formações ideológicas." (Pêcheux, 1975:162)

A primeira tese acusa a existência daquilo que Pêcheux chama de "processo discursivo". Analogamente à língua que constitui um sistema de relações entre os seus elementos (significantes), o processo discursivo consiste num sistema de relações que funciona entre os "significantes" em uma formação discursiva. Essas relações são de substituição, paráfrases, sinonímias, etc. A formação discursiva constitui, pois, o lugar da constituição dos sentidos, podendo ser considerada a matriz dos sentidos.

A segunda tese acusa a existência do interdiscurso das formações discursivas. A formação discursiva é determinada pela objetividade material contraditória do interdiscurso, que reside no fato de que "algo fala" sempre "antes, em outro lugar e independentemente", o que equivale a dizer, sob a dominação das formações ideológicas. Essa relação de dominação é contudo dissimulada no intradiscurso ou no fio do discurso de um sujeito.

O sentido, quer das palavras, quer das expressões ou proposições, tem, pois, um caráter material, já que, longe de estar vinculado à sua literalidade, está na dependência do "todo complexo com dominante" das formações ideológicas. Constitui-se num processo discursivo-ideológico.

No momento atual da análise do discurso, os sentidos continuam sendo considerados dependentes das redes de filiação 
histórica em que os discursos irrompem, um espaço de memória atravessado de divisões heterogêneas e de contradições. Tem-se que levar em conta ainda que "só por sua existência todo discurso marca a possibilidade de desestruturação-reestruturação dessas redes e trajetos" (Pêcheux, 1983b:56), o que equivale a afirmar com Bakhtin (1929) que "uma nova significação se descobre na antiga e através da antiga, mas a fim de entrar em contradição com ela e de reconstruí-la".

Os interesses atuais pelo discurso enquanto acontecimento fazem o olhar do analista se voltar, também, para os encadeamentos intradiscursivos, para as relações de significado que se estabelecem entre os enunciados no eixo horizontal dessas seqüências discursivas.

\subsection{A questão do sujeito}

Para Ducrot (1984), o sentido de um enunciado consiste numa representação (no sentido de teatro) de sua enunciação. A enunciação é o fato de um enunciado aparecer. Numa cena, movem-se os personagens, que se representam em vários níveis. Ducrot concebe o sujeito em três níveis:

1) O produtor físico do enunciado, o seu autor. Como ser empírico, é um elemento da experiência, aquele que produziu o enunciado.

2) Aquele que realiza os atos ilocutórios, ou seja, aquele que jura, promete, ameaça, pergunta, responde, etc.

3) O ser designado no enunciado como sendo seu autor, reconhecido pelas marcas de primeira pessoa. É o locutor, um ser que é, no próprio sentido do enunciado, apresentado como seu responsável, ou seja, como alguém a quem se deve imputar a responsabilidade desse enunciado. O locutor pode ser diferente do autor empírico do enunciado. Sendo uma ficção discursiva ou um ser do discurso, pertence ao sentido do enunciado e resulta dessa descrição que o enunciado dá de sua enunciação. 
O locutor se divide em duas entidades: "locutor enquanto tal" (L) e "locutor enquanto pessoa do mundo" (1), isto é, o locutor visto no seu engajamento enunciativo e o locutor visto como "pessoa completa".

4) Os enunciadores, seres que são considerados como se expressando através da enunciação, sem que para tanto se lhe atribuam palavras precisas. A enunciação é vista como expressando seu ponto de vista, sua posição, sua atitude. Correspondem ao "centro de perspectiva" de Genette (1972, apud Ducrot, 1984) ou ao "sujeito da consciência" dos autores americanos. A noção de enunciadores tem sua pertinência lingüística na ironia, na negação, nos atos de fala, nos enunciados com "mas", na pressuposição.

À mesma pessoa podem ser atribuídas as propriedades de sujeito falante, locutor e aquele que realiza os atos ilocutórios, mas nem sempre. No exemplo de Ducrot: Ah, eu sou um imbecil; muito bem, você não perde por esperar, à mesma pessoa podem ser atribuídas as propriedades de sujeito falante e locutor, mas o locutor não assume a responsabilidade do ato de afirmação realizado no primeiro enunciado. Esse ato é atribuído ao seu interlocutor.

Fazendo uma analogia com a literatura, Ducrot afirma que assim como o autor coloca em cena as personagens, o locutor, responsável pelo enunciado, dá existência, através desse, a enunciadores, de quem ele organiza os pontos de vista e as atitudes.

Ducrot distingue a polifonia no nível dos locutores e no nível dos enunciadores. A polifonia no nível dos locutores é o caso do discurso relatado em estilo direto, em que se apresenta um enunciado único, mas locutores diferentes (embora um só sujeito falante), e duas enunciações. Um primeiro locutor é responsável pelo enunciado total e um segundo locutor é responsável por parte do enunciado. Do ponto de vista empírico, temos uma só enunciação, pois do ponto de vista empírico, a enunciação é ação de um único sujeito falante, mas a imagem que o enunciado dá dela é a de troca, 
de um diálogo, ou ainda de uma hierarquia de falas. Os casos de dupla enunciação são o RED (discurso relatado direto), os ecos, os diálogos internos, os monólogos.

No discurso indireto, a polifonia ocorre com uma fronteira menos delimitada, porque o locutor incorpora lingüisticamente na sua fala a fala de um outro locutor. A diferença entre discurso relatado direto e indireto não é que o primeiro dá a conhecer a forma e o segundo apenas o conteúdo. O estilo direto implica fazer falar um outro, atribuindo-lhe a responsabilidade da fala, o que não implica que sua verdade tenha uma correspondência literal, termo a termo.

A polifonia ao nível dos enunciadores é o caso do discurso indireto livre, da negação polêmica. No discurso indireto livre, o locutor fala de perspectivas enunciativas diferentes, mas sem demarcá-las lingüisticamente. Mesclam-se, na verdade, as vozes de dois enunciadores, sem que se possa distinguir com clareza o ponto de vista ou perspectiva de onde se fala. Na negação polêmica, encena-se o choque entre duas atitudes antagônicas, atribuídas a dois enunciadores diferentes: o primeiro assume o ponto de vista rejeitado e o segundo assume a rejeição do ponto de vista.

Enquanto a teoria polifônica de Ducrot privilegia a complexidade do tecido enunciativo do discurso, a $\mathrm{AD}$, desde sua primeira época, sempre se preocupou com os processos de constituição dos sujeitos aquém de um autocontrole funcional do sujeito enunciador.

$\mathrm{Na}$ perspectiva teórica da segunda geração, o sujeito se constitui nas "evidências" produzidas pela ideologia, na dissimulação que essa faz da sua própria existência, no interior mesmo de seu funcionamento. Apaga-se o processo de assujeitamento ou o fato de que o sujeito resulta desse processo. O sujeito é explicado pelo paradoxo de um efeito retroativo, fantástico, (= efeito ideológico elementar), chamado por Pêcheux (1975) de "efeito Münchhausen", que coloca o sujeito, que tem como evidente sua origem espontânea, como origem do sujeito.

A figura da interpelação, tomada de empréstimo a Althusser (1970), explica o paradoxo ou o "efeito Münchhausen": o "não- 
sujeito" é interpelado ou constituído em sujeito pela Ideologia, todavia a interpelação faz com que todo indivíduo seja "sempre-jásujeito". O sujeito é desde sempre um indivíduo interpelado em sujeito.

O sujeito do discurso também se constitui pela interpelação e pelo esquecimento daquilo que o determina: o sujeito se identifica com a formação discursiva que o domina, ou seja, com a formação discursiva que o constitui enquanto sujeito. Os elementos do interdiscurso, sob a forma do "pré-construído" e do "processo de articulação" (ou "processo de sustentação"), são re-escritos no processo do próprio sujeito. A Ideologia, através do interdiscurso, fornece ao sujeito do discurso a sua "realidade", como um sistema de evidências.

A diferença entre esses dois elementos do interdiscurso, préconstruído e articulação, nos permite avançar na compreensão do processo pelo qual o sujeito do discurso é determinado ao mesmo tempo que "esquece" essa determinação:

“(...) O 'pré-construído' corresponde ao 'sempre-já-aî' da interpelação ideológica que fornece-impõe a 'realidade' e seu 'sentido' sob a forma de universalidade (o 'mundo das coisas'), ao passo que a 'articulação' constitui o sujeito em relação com o sentido, de modo que ela representa, no interdiscurso, aquilo que determina a

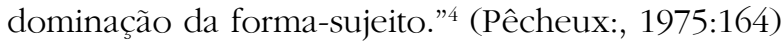

O discurso-transverso atravessa e põe em conexão entre si os elementos do pré-construído. A articulação entra em relação direta com o discurso-transverso, dado que provém da sintagmatização do discurso transverso no eixo do intradiscurso ou no fio do discurso do sujeito, o que equivale a afirmar que o discurso-transverso é o funcionamento da articulação. O interdiscurso é esquecido ou absorvido no intradiscurso, de modo que o já-dito do interdiscurso aparece como sendo o já-dito do intradiscurso, um elemento de correferência e não de determinação de sujeitos e de sentidos.

A análise do discurso em seu momento atual privilegia a questão da heterogeneidade do discurso. O interesse pela comple- 
xidade enunciativa tem sido evidenciado, nos últimos anos, pelos trabalhos de Authier-Revuz (1982), de Maingeneau (1987) e de muitos outros estudiosos. Não se trata exatamente do mesmo interesse de Ducrot, porque enquanto este se prende a uma complexidade mostrada na superfície do enunciado, Authier-Revuz e Maingeneau procuram dar conta, também, de um tipo de heterogeneidade não mostrada a nível da superfície do discurso. Essa heterogeneidade constitutiva do próprio discurso, produzida pela dispersão do sujeito, é contudo trabalhada pelo locutor de forma a fazer com que o texto adquira uma unidade e uma coerência.

A AD jamais abdicou da recusa de um sujeito intencional como fonte, ou origem enunciadora de seu discurso, mesmo em seu momento atual, em que a insistência da alteridade nas identidades discursivas coloca em causa o fechamento dessas identidades, ou seja, em que supõe a heterogeneidade enunciativa de cada seqüência analisada.

\section{A PERTINÊNCIA DA SEPARAÇÃO DE LOCUTORES E ENUNCIADORES}

A divisão do sujeito entre o sujeito falante, os locutores e os enunciadores, constitui, a nosso ver, uma via de acesso muito interessante ao discurso enquanto acontecimento. A teoria polifônica de Ducrot constitui um poderoso material para se trabalhar o discurso enquanto discurso de um sujeito. Todavia é necessário recuperar a noção de "nó na rede", que coloca o sujeito, locutor ou enunciador, na interseção de dois eixos: o eixo vertical do interdiscurso e o eixo horizontal do intradiscurso. Os sujeitos locutores e enunciadores não podem ser considerados independentes do eixo vertical desse nó, que consiste num espaço de memória de um corpo sócio-histórico, mesmo que esse corpo seja atravessado de divisões heterogêneas, de rupturas e contradições.

Na perspectiva de Ducrot, nos casos de pressuposição e nominalizações, o enunciador é assimilado a um certo se (correspondente ao on do francês). Trata-se, como diz o autor, da voz de uma 
"coletividade", "no interior da qual o locutor está localizado" (p. 216). Essa coletividade, no entanto, não tem marcas ou compromissos ideológicos, o que equivale a dizer que os enunciadores de Ducrot são vozes coletivas desligadas um corpo sócio-histórico constituído de espaços de memória.

À guisa de ilustração, retomemos a piada do teckel, contada por Ducrot (1984:199), para mostrar a pertinência do conceito de enunciador.

"Em um restaurante de luxo, um freguês sentou-se à mesa tendo como única companhia seu cachorro, um pequeno teckel. O gerente vem estabelecer uma conversação e elogia a qualidade do restaurante: "o senhor sabia que nosso mestre é o antigo cozinheiro do rei Farouk?" - "muito bem!" diz simplesmente o freguês. O gerente, sem desanimar: "e o nosso despenseiro é o antigo antigo despenseiro da corte da Inglaterra... Quanto a nosso pasteleiro, nós o trouxemos do imperador Bao-Dai". Diante do mutismo do freguês o gerente muda de conversa: "O senhor tem aí um belo teckel". Ao que o freguês responde: "Meu teckel, senhor, é um antigo São Bernardo"."

Para descrever a resposta do freguês, no quadro da teoria polifônica da enunciação, Ducrot admite que o freguês, o locutor L, expressa através de um enunciador, que é assimilado ao gerente, a opinião sobre o passado do cão. A ironia é explicada por Ducrot na assimilação da vOz do enunciador à voz do alocutário, o que se explica facilmente pelas enunciações anteriores do gerente.

Parece-nos pertinente manter que o locutor "dá existência", através dele, a enunciadores de quem organiza os pontos de vista e as atitudes. "Organiza", o que não significa "cria", porque esses pontos de vista existem como elementos do interdiscurso. A organização desses pontos de vista pertence ao locutor, como entidade do discurso enquanto acontecimento. Essa organização, no entanto, não é totalmente livre, dado que esse locutor tem uma ligação sócio-histórica com um espaço de memória, através da qual se constitui enquanto sujeito. É como sujeito que organiza as vozes 
dos enunciadores. Se faz de fato uma espécie de representação e dá a fala a diferentes personagens, ele o faz a partir de seu compromisso com um determinado lugar nesse espaço.

Não nos parece difícil manter, também, que a ironia no caso da anedota acima se explica pela assimilação da vOz do enunciador à vOz do alocutário. No entanto, deve-se considerar que também essas vozes são dependentes das redes de memória e dos trajetos sociais nos quais o discurso irrompe, ou seja, estão inscritas em determinadas filiações sócio-históricas. O discurso do gerente se constitui como um efeito de uma certa filiação, em que se defendem certos valores, como o da importância da origem dos indivíduos; o discurso do freguês, por sua vez, constitui um trabalho, consciente e deliberado, de desestruturar as redes dessa filiação, ao mesmo tempo que se filia a outras, o que equivale a dizer que esse espaço de memória (de um corpo sócio-histórico) está atravessado de divisões heterogêneas.

No enunciado do freguês ouvem-se, na verdade, duas vozes: uma que reafirma os valores defendidos pelo gerente (o enunciador se assimila ao alocutário, como quer Ducrot); outra que mostra o absurdo desses valores (esse enunciador se assimila ao freguês). A reafirmação dos mesmos valores defendidos pelo gerente (a importância da origem dos indivíduos) é enunciada pelo freguês, considerando-se enquanto "indivíduo" um cachorro teckel (colocado no mesmo nível que um mestre de cozinha, um despenseiro, um pasteleiro). Ora, se até mesmo um cachorro teckel tem uma origem importante, não há neste mundo quem ou o que não o tenha, e seria, portanto, uma imbecilidade defender tais valores.

\subsection{A negação}

A negação, sobretudo a polêmica, também pode ser explicada através da separação de locutores e enunciadores. Maingeneau (1987) assume com Ducrot que a maior parte dos enunciados negativos pode ser analisada como encenação do choque entre duas 
atitudes antagônicas, atribuídas a dois enunciadores diferentes: o primeiro assume o ponto de vista rejeitado e o segundo assume a rejeição do ponto de vista. Vejamos um exemplo:

"Jeová criou a mulher Eva usando como base uma costela de Adão. Desse modo, Eva era da mesma 'espécie' que Adão. Não era um animal inferior,' mas sim 'osso dos [seus] ossos e carne de [sua] carne'." (A Sentinela, vol. 110, nº 10)

No enunciado negativo em questão pode-se ouvir a voz de um enunciador, à qual a voz do locutor se assimila, que afirma que a mulher não era um animal inferior. Além dessa voz, ouve-se a vOz de um outro enunciador, que afirma o contrário. Em outras palavras, o enunciado negativo coloca em jogo o discurso-outro - seu avesso - enquanto presença virtual na sua materialidade descritível.

Essas vozes estão inscritas num espaço contraditório de filiações, espaço social e de memória histórica. Toda formulação está colocada na intersecção de um eixo vertical com um eixo horizontal. O eixo vertical, conforme temos repetido, é o da rede interdiscursiva de formulações, da qual o enunciado é uma invariante. O enunciado se insere numa rede de formulações algumas das quais são dominadas pela mesma formação discursiva, aquela que domina a seqüência de onde é tirado (seqüências produzidas nas condições de produção homogêneas); outras às quais o enunciado pode oporse, referir-se implicitamente ou modificar, podem ser produzidas em condições de produção heterogêneas em relação às primeiras. $O$ eixo horizontal, por sua vez, é o eixo da linearidade do disurso, ou do intradiscurso: o enunciado acha-se relacionado com outros enunciados no intradiscurso de uma seqüência discursiva.

No nosso exemplo, o locutor responsável se identifica com o enunciador que afirma que "a mulher não era um animal inferior", o que equivale a dizer que seu enunciado se insere numa rede de formulações dominadas por um discurso não machista. Todavia se considerarmos o enunciado na sua relação com os demais enunciados do intradiscurso, essa identificação se torna questionável, já que 
no eixo horizontal do intradiscurso o locutor responsável se oculta atrás de um outro locutor (Deus), um locutor, diga-se de passagem, inquestionável, que afirma a condição de inferioridade da mulher como "complemento" e "ajudadora" do homem e não como uma "competidora":

"Deus disse que a mulher seria ajudadora e complemento do homem. (...)Eva seria "um complemento", não uma competidora. A família não seria como um navio com dois comandantes rivais, pois a chefia seria exercida por Adão - 1 Coríntios 11:3; Efésios 5:22; 1 Timóteo 2:12, 13." (A Sentinela, vol. 110, ํㅡ10)

Esses enunciados do intradiscurso, atribuídos a Deus, são produzidos em condições de produção homogêneas com "a mulher era um animal inferior", discurso-outro do enunciado negativo, presença virtual na sua materialidade descritível, e em condições heterogêneas com "a mulher não era um animal inferior".

Essa análise serve para elucidar que o espaço de memória que constitui esse discurso está atravessado de divisões heterogêneas, de rupturas e contradições. O discurso de A Sentinela trata-se, sem dúvida, de um espaço discursivo de equivocidade, que foge a qualquer domínio daquilo que Pêcheux (1983b) chama de "logicamente estabilizado", no qual todo enunciado produzido deveria refletir propriedades estruturais independentes de sua enunciação.

Num espaço discursivo logicamente estabilizado, uma entidade qualquer não pode ter ao mesmo tempo a propriedade $\mathrm{P}$ e a propriedade não-P (no caso do nosso exemplo, a mulher não pode ter a propriedade de inferioridade e não-inferioridade em relação ao homem). Todavia a religião, apoiada na Bíblia, se apresenta como uma "ciência régia", uma espécie de "organon", com a promessa de estruturar o real de modo a livrá-lo de toda falsa-aparência, de lhe assegurar o controle num espaço coerente sem contradições, descrevendo-o sem risco de interpretação.

Essa falsa aparência de homogeneidade lógica todavia pode ser denunciada por essa nova maneira de ler as materialidades orais e 
escritas através das vozes dos locutores, e sobretudo das vozes dos enunciadores, que indicam a presença de não-ditos no interior daquilo que é dito. Todo enunciado ou seqüência de enunciados é lingüisticamente descritível como uma série de "pontos de deriva possíveis". A análise do discurso tem justamente por objeto trabalhar o espaço de interpretação deixado por esses pontos de deriva.

A contribuição de Ducrot se faz muito importante para se trabalhar as formas lingüístico-discursivas do discurso-outro, no entanto não se pode perder de vista a existência das filiações sóciohistóricas, a sua organização em memórias e a relação dos locutores e enunciadores com essas filiações.

\subsection{Enunciados com mas}

Ducrot descreve os enunciados com mas dizendo que eles colocam em cena dois enunciadores, que enunciam em sentidos opostos. O locutor responsável se identifica com um dos enunciadores e se distancia do outro.

Como vimos afirmando, os enunciadores de Ducrot sempre se circunscrevem ao contexto mais imediato de discurso. Quando não constituem a voz do locutor, ou do alocutário, constituem a voz de uma coletividade, no interior da qual o locutor se localiza. Essa coletividade é o alcance social máximo que o conceito de enunciador de Ducrot comporta.

Muitas vezes, para limitar a identificação do enunciador aos interlocutores, Ducrot lança mão de recursos expressivos como o uso de certamente: Em "Certamente o tempo está bom, mas estou com problema nos pés", diz Ducrot, o locutor se assimila a E2, assimilando seu alocutário a E1, que afirma que o tempo está bom. Embora o locutor se declare de acordo com o fato alegado por E1, ele se distancia deste. Ao reconhecer que faz bom tempo, não o afirma por sua própria conta. Essa distinção, argumenta Ducrot, é imposta pela significação da frase, e, mais precisamente pelo emprego de certamente, que marca um acordo tardio com a asserção. 
Para nós parece certo que esse trabalho de procurar pistas na frase (enquanto entidade lingüística) ou instruções que nos levem ao sentido do enunciado e à distinção entre locutores e enunciadores, assim como a procurar as indicações a quem devemos atribuir esses papéis, abre perspectivas de análise. Todavia essas pistas devem ser tomadas, também, como instruções para se descobrir como o enunciado em sua materialidade descritível, enquanto entidade lingüística, mas também enquanto elemento inscrito na bistória, pode colocar em jogo o seu discurso-outro - seu avesso.

Os enunciados com mas constituem de fato um material de interesse para o analista do discurso, já que constituem uma forma lingüisticamente privilegiada de ocultar não-ditos constitutivos daquilo que é dito. Assim, é comum o membro do enunciado introduzido por mas aparentar refutar o primeiro membro do enunciado, quando, na verdade, refuta um não-dito, que pode ser um pressuposto ideológico.

O enunciado "Ela é mulher, mas é inteligente", enunciado bastante comum no discurso cotidiano do brasileiro (e pressupõese que seja comum em muitas outras culturas), coloca como espaço virtual de leitura um discurso-outro, discurso machista, que afirma que "toda mulher é burra".

O enunciador que "afirma" o não-dito "toda mulher é burra" não se limita no entanto ao alocutário ou a um SE. Mesmo que possa ser assimilado ao alocutário, caso que se explicaria facilmente, segundo Ducrot, através de certamente, "Certamente ela é mulher, mas é inteligente", esse enunciador extrapola os limites do contexto mais imediato do discurso. Locutores, alocutários e enunciadores se inscrevem em redes de filiações sócio-históricas.

\subsection{As palavras entre aspas}

De acordo com Authier-Revuz, as aspas constituem um sinal a ser decifrado pelo analista. Consideremos o valor das aspas nesses exemplos: 
“(1) Em 1997, a atenção dos EUA voltou-se novamente para a questão da escravatura, pelo menos em suas 'modernas' encarnações.

(2) Aqui os escravos, descendentes de gerações de 'propriedades' humanas, não recebem salário nem nenhum tipo de educação. Não podem se casar sem autorização nem planejar o futuro dos filhos."

Poderíamos ver aí, considerando a teoria polifônica de Ducrot, a presença de dois enunciadores, cada qual atribuindo um sentido diferenciado às expressões aspeadas. No exemplo (1), um enunciador enuncia a existência de versões modernas de escravidão. Um outro enunciador critica a existência de escravidão na modernidade, já que modernidade e escravidão são conceitos incompatíveis. Esses enunciadores se inscrevem em lugares diferentes. Poderíamos dizer que ao primeiro não compete posicionar-se, mas simplesmente repetir as expressões tal como elas têm sido empregadas nos discursos que tratam da questão; jornais, revistas. O segundo enunciador deixa marcada a sua posição pela crítica que faz, ou pela indignação que expressa. No exemplo (2), o processo é semelhante. Um primeiro enunciador fala da existência de seres humanos propriedades de outros seres; um segundo enunciador denuncia o fato de seres humanos estarem sendo tomados como propriedades de outros.

Pensamos que seríamos fiéis a Ducrot se atribuíssemos a L, locutor enquanto tal, visto em seu engajamento enunciativo, a crítica ou a indignação nos exemplos acima; e a $\lambda$, locutor enquanto ser do mundo, o fato de enunciar, locutor que, entre outras propriedades, tem a de ser a origem do enunciado.

No entanto, para sermos analistas do discurso, isso seria muito pouco, dado que a "voz" de $\lambda$, como a de $L$, se inscrevem em filiações sócio-históricas de identificação, não podendo ser consideradas neutras. Seria mais adequado ver esses enunciados filiados a um espaço de memória heterogêneo, marcado por contradições, e dois enunciadores antagônicos inscritos na divisão desse espaço. 
É possível todavia que essa necessidade de relacionar as vozes dos locutores e enunciadores a uma filiação sócio-histórica coloque em causa a distinção entre $L$ e $\lambda$. Mas esta é uma questão que precisa ser aprofundada.

\section{CONSIDERAÇÕES FINAIS}

Procuramos mostrar que, no desenvolvimento atual das pesquisas sobre os encadeamentos intradiscursivos, interfrásticos, que permite, como diz Pêcheux (1983), abordar o estudo da construção dos objetos discursivos e dos acontecimentos, e também dos pontos de vista e lugares enunciativos no fio do intradiscurso, o trabalho de Oswald Ducrot muito contribui para a compreensão das formas lingüistico-discursivas do discurso-outro, entendendo-se por discurso-outro tanto o discurso de um outro, colocado em cena por um sujeito, como o discurso do sujeito se colocando em cena como um outro.

Todavia a heterogeneidade, argumentamos, extrapola o plano da heterogeneidade mostrada, ou da polifonia, isto é, existe na insistência de um interdiscurso que se impõe, aquém de todo autocontrole funcional do sujeito enunciador, e que vem estruturar e ao mesmo tempo desestabilizar as seqüências discursivas colocadas em cena por esse sujeito.

É em função dessa heterogeneidade constitutiva que afirmamos neste trabalho a necessidade de marcarmos uma diferença entre o conceito de polifonia de Ducrot e o conceito de heterogeneidade da $\mathrm{AD}$. Mas mesmo que tomássemos somente o caso da heterogeneidade mostrada, tal como ela é tratada no interior da AD, ainda haveria diferenças, dado que todo enunciado deve ser considerado na intersecção dos dois eixos, o do intradiscurso e o do interdiscurso, como "nó numa rede", o que faz com que a heterogeneidade mostrada num enunciado extrapole os limites de sua relação com esse enunciado, entrando, juntamente com ele, na rede vertical do interdiscurso e na horizontal do intradiscurso. 
Ao mantermos que o discurso, mesmo enquanto acontecimento, não é "um aerólito miraculoso, independente das redes de memória e dos trajetos sociais nos quais ele irrompe" (Pêcheux, 1983b:56), estamos procurando preservar a própria identidade da AD com relação ao espaço de memória em que ela própria se constitui.

A teoria polifônica de Ducrot se coloca, na sua relação de alteridade com a $\mathrm{AD}$, como um elemento enriquecedor para a análise lingüístico-discursiva. A separação das figuras dos locutores e enunciadores nos parece de fato uma proposta muito interessante para explicar os casos de ironia, pressuposição, negação, os atos ilocutórios, o "mas", as nominalizações. Acrescentamos a essa lista, por nossa conta, alguns dos casos que Authier-Revuz (1982) classificou como "conotação autonímica" (palavras marcadas com aspas, itálicos, negritos). Vimos a pertinência dos enunciadores em alguns desses casos de heterogeneidade, tornando, porém, os enunciadores mais comprometidos com a perspectiva sócio-histórica que defendemos.

De qualquer forma, é possível dizer que Oswald Ducrot se coloca para a AD não como um rival, mas como um interlocutor interessante.

\section{NOTAS}

${ }^{1}$ Ducrot vai no entanto admitir a dificuldade de se poder segmentar um "texto" numa pluralidade de enunciados sucessivos, reconhecendo que "o que se chama de 'texto', é, na verdade, habitualmente, um discurso que se supõe ser objeto de uma única escolha, e cujo fim, por exemplo, já é previsto pelo autor no momento em que redige o começo" (Ducrot, 1884:166).

${ }^{2}$ Do mesmo modo, Foucault não tem um sentido histórico de enunciação, enquanto determinada socialmente. Para Foucault, a .enunciação se caracteriza por sua individualidade espaço-temporal. Daí afirmar que a enunciação é um acontecimento que não se repete, tendo uma singularidade situada e datada que não se pode reduzir.

${ }^{3}$ Em memória do barão que, puxando os próprios cabelos, levanta-se nos ares. 
${ }^{4}$ Entende-se por "forma-sujeito" o sujeito do discurso identificado com a formação discursiva que o determina.

5 Grifo nosso.

${ }^{6}$ Trechos de dois textos publicados no Estado de São Paulo, de 23/11/97: "Escrava Fatma não sabe o que é liberdade", "Escravagismo, o mal que teima permanecer no mundo".

\section{REFERÊNCIAS BIBLIOGRÁFICAS}

ALTHUSSER, L. Ideologia e aparelhos ideológicos de Estado. Lisboa, São Paulo: Presença-Martins Fontes, 1974. (trad. de Idéologie et appareils idéologiques d'État, 1970).

AUTHIER-REVUZ, J. Hétérogénéité montrée et hétérogénéité constitutive: éléments pour une approche de l'autre dans le discours. DRLAV 26. Paris. p.91-151, 1982.

. Hétérogénéité(s) énonciative(s). Langages, 73. Paris. p.98-109, 1984.

BAKHTIN, M. Marxismo e Filosofia da Linguagem. 4. ed. São Paulo: Hucitec. 1988 (trad. bras. com base na trad.francesa, de 1977, do original russo de 1929).

COURTINE, J.J. Analyse du discours politique (le discours communiste addressé aux chrétiens). Langages 62. Paris: Dedier-Larousse.

DUCROT, O dizer e o dito. Campinas: Pontes, 1987. (trad. de Le dire et le dit, 1984).

FOUCAULT, M. A arqueologia do saber. 3. ed. Rio de Janeiro: ForenseUniversitária, 1987, (trad. de L’archéologie du Savoir, 1969).

. L'Ordre du discours. Paris. Gallimard. 1971.

GADET, F. \& HAK. T. (Org.s.). Por uma análise automática do discurso. Uma introdução à obra de Michel Pêcheux. Campinas: UNICAMP, 1990 (trad. bras. de Towards an automatic discourse analysis).

MAINGENEAU, D. Novas tendências em análise do discurso. Campinas: Pontes, 1989 (trad. bras. de Nouvelles tendances en analyse du discours, 1987).

- O contexto da obra literária. Campinas: Pontes, 1995 (trad. bras. de Le contexte de l'oeuvre littéraire. 1993).

. Elementos de lingüistica para o texto literário. São Paulo: Martins Fontes, 1996 (trad. bras. de Éléments de linguistique pour le texte litéraire, 1990). 
MAINGENEAU, D. Pragmática para o discurso literário. São Paulo: Martins Fontes, 1996 (trad. bras. de Pragmatique pour le discours litéraire, 1990).

PÊCHEUX, M. Analyse automatique du discours, Paris: Dunod, 1969.

Semântica e discurso: uma crítica à afirmação do Óbvio, Campinas: UNICAMP, 1988 (trad. de Les Vérités de la Palice, 1975).

- A análise de discurso: três épocas, reproduzido in Por uma análise automática do discurso - uma introdução à obra de Michel Pêcheux, Campinas: UNICAMP, 1990 (trad. bras. 1983a).

. O discurso: estrutura ou acontecimento. Campinas: Pontes, 1990 (trad. de Discours: structure or event 1983b). 